\title{
ANGIOFIBROMA OF NASAL SEPTUM: A CASE REPORT
}

V. U. Shanmugam¹, B. Krishnaswamy², Ruta Shanmugam³ ${ }^{3}$ R. G. Mariappan4, Balaji Swaminathan ${ }^{5}$, N. Srikanth6, M. S. Kandasamy Kamindan7, M. Valluvan ${ }^{8}$

\section{HOW TO CITE THIS ARTICLE:}

V. U. Shanmugam, B. Krishnaswamy, Ruta Shanmugam, R. G. Mariappan, Balaji Swaminathan, N. Srikanth, M. S. Kandasamy Kamindan, M. Valluvan. "Angiofibroma of Nasal Septum: A Case Report”. Journal of Evolution of Medical and Dental Sciences 2014; Vol. 3, Issue 51, October 09; Page: 12032-12035,

DOI: $10.14260 /$ jemds/2014/3587

ABSTRACT: Angiofibroma is an uncommon benign tumor seen in adolescent males. Extra nasopharyngeal angiofibroma although rare, has also been reported. Nasal cavity, Nasal septum, Para nasal sinuses are some of the common extra nasopharyngeal sites of origin, and can present a diagnostic challenge. Hence, meticulous evaluation and the possibility of angiofibroma should be always kept in mind. We present a rare case of Nasal Septal Angiofibroma in a 13-year-old boy with 1-month history of epistaxis and nasal obstruction and were treated successfully.

KEYWORDS: Benign tumors of nasal cavity, Angiofibroma, Extra nasopharyngeal angiofibroma, Nasal septum.

INTRODUCTION: Juvenile angiofibroma has been recognized since the ancient times of Hippocrates. It is an extremely vascular, uncommon, benign tumor that arises in the tissues within the sphenopalatine foramen. Rarely, it is found at other sites in the nasal cavity and Paranasal sinuses. ${ }^{1}$ Extra nasopharyngeal angiofibroma has also been reported arising from the hypopharynx, ${ }^{2}$ facial nerve, lacrimal sac, trachea, esophagus. ${ }^{3}$

Although Histopathologically they are labeled benign, their tendency to recur and spread aggressively carries a potential risk. ${ }^{4}$ Gender, age, prevalence, affected site, pathogenesis, clinical and CT features and recurrence are completely different from the Juvenile Angiofibroma 5 .Objective of this case report is to report Angiofibroma arising from nasal septum which is not a conventional site for the same.

CASE PRESENTATION: A 13-year-old boy complained of recurrent episodes of epistaxis from the right nasal cavity and progressive nasal obstruction. Nasal endoscopy showed a single, pinkish red, sessile, smooth, non-friable and non-ulcerated mass arising from the anterior $1 / 3^{\text {rd }}$ of the nasal septum. Computed Tomography showed, a soft tissue mass of size $15^{*} 6 * 5.7 \mathrm{~mm}$ arising from the right nasal septum. We performed an endoscopic removal of the mass. Postoperative period was uneventful. The lesion was then Histopathology reported as Angiofibroma.

MACROSCOPY: A grey white polypoidal soft tissue piece measuring $1.5 \times 0.5 \mathrm{cms}$ and on cut section solid grey white areas identified.

MICROSCOPY: Respiratory epithelium lined soft tissue where spindle shaped cells are present. The spindle shaped cells have comma shaped to blunt cigar shaped nucleus. Vascular spaces are seen in between and at places they resemble a stag-horn. 
DISCUSSION: Juvenile Nasopharyngeal Angiofibroma is the most common benign neoplasm of the nasopharynx, despite representing less than $0.05 \%$ of tumors of the head and neck. ${ }^{5}$ The initial growth of JNA follows a well-defined pattern in the pterygo palatine fossa, nasopharynx and nasal cavity. ${ }^{5}$ The most common site of extra nasopharyngeal angiofibroma is the maxillary sinus. $2,3,5,6,7$

ENPA's etiology is associated with a migration error of the fascia basalis, justifying its presence in varied locations. ${ }^{5}$

Unlike classic juvenile angiofibromas, extra nasopharyngeal angiofibroma tends to occur in the later stages of life and it is more commonly seen in females. ${ }^{4,8,9}$ However, it is unclear why there is discrepancy in age of presentation and sex predilection between the two different types of Angiofibromas. ${ }^{7}$ Based on the nature and location of the tumor, the presenting symptoms are highly variable. Tumors with intranasal origin may present earlier. ${ }^{8}$ Anterior rhinoscopy and or nasal endoscopy reveals a polypoidal or fleshy mass with smooth or ulcerative surface filling the nasal cavity. 4

Computed Tomography helps to delineate tumor extensions ${ }^{4}$.MRI and Carotid angiograms are also helpful in confirming diagnosis. ${ }^{8}$ Surgical removal still remains the mainstay of the treatment.2,4,5,8 The surgical approach is determined by the size, location, and vascularity of the tumor. Recurrence is rare extra nasopharyngeal angiofibromas.

In contrast to some of the existing literature, which states ENPA, occur in later stages of life and more common in females, our patient is an adolescent male presenting with Angiofibroma arising from the nasal septum. The intra operative bleeding was minimal. Tumor was completely excised under nasal endoscopy. The patient is free from any symptoms on follow up.

REMARKS: Extra nasopharyngeal angiofibroma is an entity on its own and should be considered in a differential diagnosis of vascular tumors of nose. Nasal septum must be considered as a potential site of origin. This case is being presented for its rarity.

\section{CLINICAL PICTURE:}

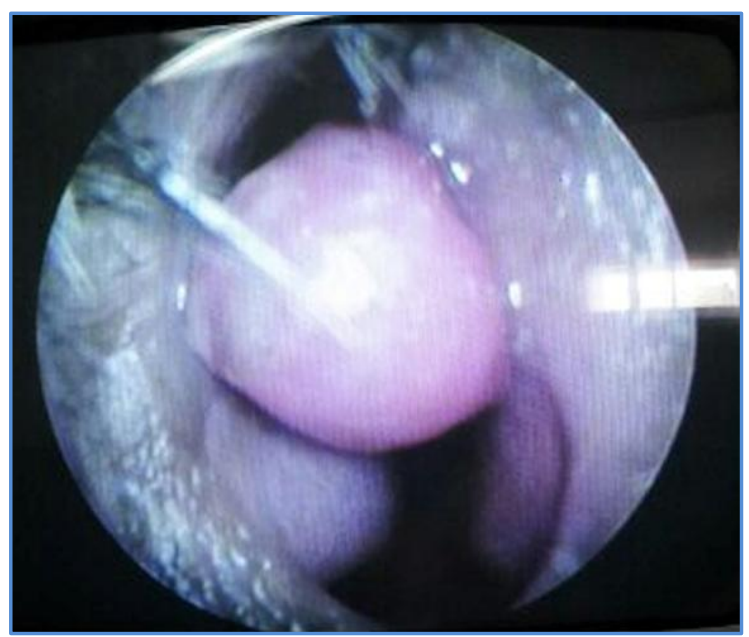

\footnotetext{
Fig. 1: Nasal Endoscopy shows smooth, sessile, non-ulcerative mass arising from the nasal septum on Right side
} 


\section{MICROSCOPIC PICTURES:}

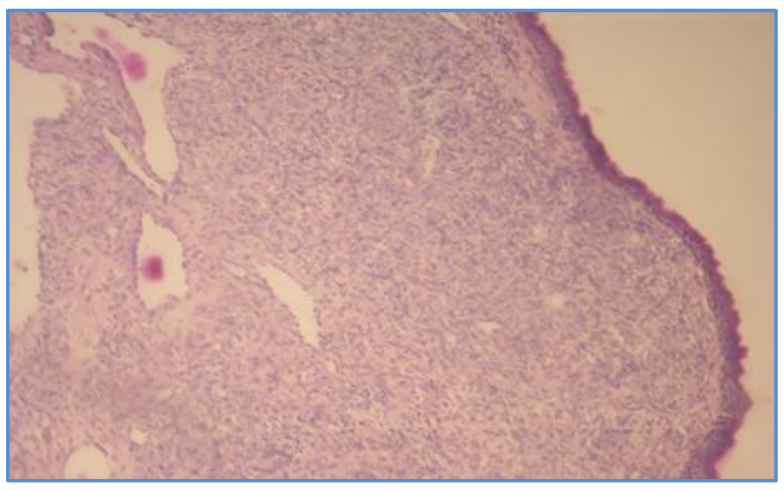

Fig. 1: Respiratory epithelial lining and spindle shaped cells

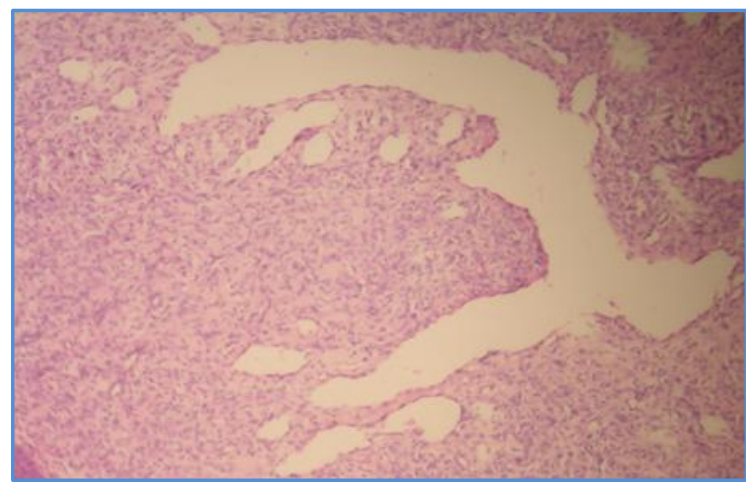

Fig. 2: vascular spaces appears like the stag-horn

\section{REFERENCES:}

1. Shaheen O H. Angiofibroma. Scott Brown's Otorhinolaryngology Head \& Neck Surgery, $6^{\text {th }}$ ed.5/12/1-5/12/6.

2. Shun-Ta Hsieh, Yuan-Ching Guo, Tung-Lung Tsai, Winby York-Kwan Chen, Jui-Lin Huang. Angiofibroma of the Hypopharynx. J Chin Med Assoc 2004; 67: 373-375.

3. Anna Szymanska, Marcin Szymanski, Kamal Morshed, Elzbieta Czekajska - Chehab, Małgorzata Szczerbo-Trojanowska. Extranasopharyngeal angiofibroma: clinical and radiological presentation. Eur Arch Otorhinolaryngol (2013) 270: 655-660.

4. Abdul Latif hamdan, Roger V. Moukarbel, Mireille Kattan, Mohamad Natout. Angiofibroma of the nasal septum. Middle East journal of Anaesthesiology 21 (4), 2012: 653-656.

5. Felipe Gustavo Correia et al. Extranasopharyngeal angiofibroma of the nasal septum uncommon presentation of a rare disease. Braz J Otorhinolaryngol. 2013; 79 (5): 646.

6. Anand S, G. B. Singh, Sunil Garg, Garima Yadav, Mayank Yadav. Extra nasopharyngeal angiofibroma of nasal septum. National Journal of Otorhinolaryngology and Head \& Neck Surgery, Vol. 1 (10) No. 1, April 2013.

7. Surinder K. Singhal, Nitin Gupta, Hitesh Verma, Arjun Dass, Amarinder Kaur. Extra nasopharyngeal angiofibroma: Report of two cases. Egyptian Journal of Ear, Nose, Throat and Allied Sciences (2014) 15, 73-76.

8. Robert Y Huang, Edward J Damrose, Keith E. Blackwell, Alen N. Cohen, Thomas C. Calcaterra. Extra nasopharyngeal angiofibroma. International Journal of Pediatric otorhinolaryngology, 59 (2000); 59-64.

9. Tasca I, G. Ceroni Compadretti. Extra nasopharyngeal angiofibroma of nasal septum. A controversial entity. Acta Otorhinolaryngology Italica 2008; 28: 312-314. 


\section{AUTHORS:}

1. V. U. Shanmugam

2. B. Krishnaswamy

3. Ruta Shanmugam

4. R. G. Mariappan

5. Balaji Swaminathan

6. N. Srikanth

7. M. S. Kandasamy Kamindan

8. M. Valluvan

\section{PARTICULARS OF CONTRIBUTORS:}

1. Professor \& Unit Chief, Department of ENT, Rajah Muthiah Medical College and Hospital.

2. Professor, Department of Pathology, Rajah Muthiah Medical College and Hospital.

3. Professor \& HOD, Department of ENT, Rajah Muthiah Medical College and Hospital.

4. Professor, Department of ENT, Rajah Muthiah Medical College.

5. Reader, Department of ENT, Rajah Muthiah Medical College.
6. Lecturer, Department of ENT, Rajah Muthiah Medical College.

7. Post Graduate, Department of ENT, Rajah Muthiah Medical College.

8. Post Graduate, Department of Pathology, Rajah Muthiah Medical College.

\section{NAME ADDRESS EMAIL ID OF THE CORRESPONDING AUTHOR:}

Dr. Kandasamy Kamindan,

Post Graduate,

Department of ENT,

Rajah Muthiah Medical College,

Annamalai Nagar,

Chidambaram,

Tamil Nadu-608002.

Email: kamindan@gmail.com

Date of Submission: 23/09/2014.

Date of Peer Review: 24/09/2014.

Date of Acceptance: 01/10/2014.

Date of Publishing: 09/10/2014. 